\title{
Gender Relations in Environmental Entitlements: Case of Coastal Natural Resources in Tanzania
}

\author{
Albinus M.P. Makalle ${ }^{1}$ \\ ${ }^{1}$ Institute of Human Settlement Studies, Ardhi University, Dar es Salaam, Tanzania \\ Correspondence: Albinus M.P. Makalle, Institute of Human Settlement Studies, Ardhi University, Dar es Salaam, \\ Tanzania. E-mail: makalle@udsm.ac.tz
}

Received: June 4, 2012 Accepted: October 20, 2012 Online Published: November 20, 2012

doi:10.5539/enrr.v2n4p128

URL: http://dx.doi.org/10.5539/enrr.v2n4p128

\begin{abstract}
The paper is about a study that rested on the mapping of how men and women gain entitlements (access to, ownership and control) of coastal resources through endowments, referred to herein as environmental entitlements. Environmental entitlements are enhanced by institutional means and mechanisms and the policy dimension of which demand specific forms of action to promote and protect them. The central role played by institutions (regularised patterns of behaviour between men and women in society) in bringing about changes to the environment and society relationships, was the premises of the study. The study explored on how men and women command natural resources that are instrumental to their wellbeing (van Ingen, Kawau, \& Wells, 2002). A combination of data collection techniques were used, which included in-depth household interviews, focus group discussions, participant observations, and documentary review to capture the understanding of the relationship between environmental entitlements and gender roles. Various alternative conceptualisations of gender-environment relations, which can roughly be thought of as translations of the findings into the environment domain, were also used. As an action research, it highlighted a number of empowerment issues for participatory implementation with the focus on women. This is in recognition that there is undervaluation of both environmental resources and of women's labour in managing and conserving these.
\end{abstract}

Keywords: gender, gender relation, endowment, coastal natural resource, environmental

\section{Introduction}

The coastline of Tanzania (Annex 1) is an endowed environment with scenic, diverse and rich resources making it a unique part of the land and a potential livelihood source. It is established that the coast also has a chain of essential natural systems, embracing widespread beaches, estuaries, mangrove trees, seagrass beds, and coral reefs (TCMP, 2003; Torell, Mwanahija, Julius, Kalangahe, \& Munubi, 2007). As well as endangered species (e.g. the dugong and loggerhead turtle - Caretta caretta) for specific consideration, many of the livelihoods adopted by people in coastal communities in Tanzania are on the use of these rich environmental resources differently (Francis \& Bryceson, 2001). Despite of this richness, the socio-economic studies of Tanzania coastal areas (Francis \& Bryceson, 2001; TCMP, 2003; Sesabo \& Tol, 2005) have shown that most of its communities are exceptionally poor.

Furthermore, an increased threat upon the coastal environmental resources due to increased development activities is threatening sustainable socio-economic development of the vast majority of coastal communities (Francis \& Bryceson, 2001; Masalu, 2002; Andersson \& Ngazi, 1998). With increasing "development", expanding population and greater competition for all resources, more and more of the resources on which the poor depend, especially the vulnerable groups like women and children, would end up being "claimed" by the less poor. The development-environment interactions, taking place on the coast, are also felt right through the community. Many of the livelihoods, adopted by people in coastal communities are based on the use of different natural resources, depending on environmental entitlements on one hand and gender relations on the other.

In the context, of the study environmental entitlements referred to the bundles of rights and arrangements by which poor people access, own and control coastal natural resources. The ensuing benefits and associated decision-making are gender based. Gender relations, within the context of environmental entitlements, referred to women's and men's roles and responsibilities in access, ownership and control over resources that shape activities affecting the environment. This is because access to or control over resources determines the level of 
equality achievable by an individual within the community.

Studies (Agrawal, 2001) have shown that access to, ownership and control over natural resources also relate to the changing values of resources and men and women's roles. Men and women command different gender based roles, responsibilities, knowledge and decision making opportunities with respect to environmental entitlements. Van Ingen et al. (2002) observed that men and women differ in resource use patterns, access to and control over natural capital and other assets capital namely human, financial, physical, and social.

Some scholars (Anderson \& Ngazi, 1998; Semesi, 1998; TCMP, 2000; Tietze, Groenewold, \& Marcoux, 2000; Jidawi \& Ohman, 2002) have conducted studies in the Tanzania coastal areas on coastal resources. However, gender equity in access to, ownership and control over the coastal natural resource was less attended. Importantly is to understand how women and men's relationships to the access to, ownership and control over natural resources plays a vital role in developing solutions not only for more sustainable use of resources but equitable entitlements. Partly the issue is addressed in other studies, which include analysis of coastal communities in Tanzania (TCMP, 2003; Sesabo \& Tol, 2005); and two studies on gender and livelihood in coastal villages in Tanzania (van Ingen et al., 2002; Sobo, 2003).

All these studies fell short to bring to light the relative importance of different component dimensions of access to, ownership and control over natural resources that have a bearing on gender equity for sustainable natural resource management and how can they be taken into account in development interventions, the focus of this paper.

\section{Method}

\subsection{Study Area}

Bagamoyo (Annex 2) district in Pwani region had 173,885 inhabitants in 1988, 228,967 in 2002 and estimated 248,328 in 2005 . These are equivalent to 27.8 percent, 25.8 percent and 23.4 percent of total regional population for the year 1988, 2002 censuses and 2005 projection respectively (URT, 2007). Population census of 2002 (URT, 2002) records that the number of females exceeds that of males in Pwani region. As a result, women economic groups are well established. Pwani region possessed 986 women economic groups in 2007 out of which 16.8\% (166) were in Bagamoyo.

The Tanga study site is in Tanga region (Annex 3), which is located in the East of Tanzania Mainland. In 2007 the region had a GDP per capita income of TZS 268,944 (app. US\$ 234 by 2007 prices), making it one of the poorest regions in Tanzania Mainland. It compared unfavourably with regions like Dar es Salaam (US\$ 609), Iringa (US\$ 397) and Ruvuma (US\$ 389) (URT, 2007). The area of Tanga Region which is covered by water is $2.1 \%\left(572 \mathrm{~km}^{2}\right.$ of $27,342 \mathrm{~km}^{2}$ total area), mainly in Tanga peri-urban and Pangani district. The 2002 Tanzania national census showed Tanga region had 1,636,280 people of which 793,159 were males and 843,121 were females, with an annual growth rate of $1.8 \%$.

Kigamboni (South Beach) is a beach front suburb on a peninsula with very beautiful, sandy beaches located in Temeke Municipal of Dar es Salaam city (Annex 4), Tanzania. Dar es Salaam is one of the fastest growing cities in Sub Saharan Africa. The 2002 national census showed that Dar es Salaam city had a population of 2,487,288 $(1,254,853$ males and the rest females). Temeke Municipal had 768,451 (31\% of the population of Dar es Salaam city). Females accounted for about half (49.6\%) of the population of Temeke Municipal.

\subsection{Research Design}

The research design was a case study using a combination of qualitative and quantitative sample survey complementing participatory methods for data collection. The case studies were the coasts of Dar es Salaam, Pwani, and Tanga regions in Tanzania. The study also took a descriptive approach to understand how, under given institutional, legal and cultural settings, men and women do or do not equally share the benefits of the coastal natural resource for their survival. A gender analysis was used to uncover complexities of natural resource-use decisions at the household scale. Major issues here were the division of labour, power/control over resources, and social, political and economic hierarchies.

\subsection{Sampling}

In addition to the favourable gender information presented in section 3.1 for the study, the selection of the regions was also based on logistics of cost and time. The rationale was that these regions represent divergent richness in costal natural resources that is exploited by coastal people as livelihood source. The selected sample survey was to generate detailed information about a population from a small sample, so minimising costs and resource requirements. 
In this study, a household was the unit of analysis. A household sample for the study was selected using stratified and random sampling techniques. In each district at least three villages/sites were chosen for study. The villages selected were those which represented more the general characteristics of the coastal area in question. Ten villages were selected in Bagamoyo site and three wards of Kigamboni, whereby a total of 100 households were interviewed. In Tanga 15 households were selected in each of the three different wards along the coast, with the help of the Tanga Coastal Zone Management to represent an array of coastal resources.

The selected households were then classified according to wealth status based on resource endowment classification (Table 1). The classification done participatory, during pre-testing of the questionnaire, was at three levels of high, medium and low based on respondents perception response as to who is rich or poor.

Table 1. Resource endowment classification

\begin{tabular}{|c|c|c|c|c|}
\hline Criteria & High Resource Endowment & $\begin{array}{l}\text { Medium } \\
\text { Endowment }\end{array}$ & Resource & $\begin{array}{l}\text { Low } \\
\text { Endowment }\end{array}$ \\
\hline $\begin{array}{l}\text { Physical } \\
\text { endowment }\end{array}$ & $\begin{array}{l}\text { - Modern fishing gear } \\
\text { - Agricultural land more than } \\
\text { acres } \\
\text { - Developed social network }\end{array}$ & $\begin{array}{l}\text { - Traditional f } \\
\text { - Marginal } \\
\text { land } \\
\text { - Fragmented } \\
\text { network }\end{array}$ & $\begin{array}{r}\text { fishing gear } \\
\text { agricultural } \\
\text { social }\end{array}$ & $\begin{array}{l}\text { - No fishing gear } \\
\text { - Landless } \\
\text { - broken down social } \\
\text { network }\end{array}$ \\
\hline $\begin{array}{l}\text { Type of house } \\
\text { owned/living in }\end{array}$ & $\begin{array}{l}\text { - Corrugated iron roof } \\
\text { - Painted walls } \\
\text { - Cemented floor } \\
\text { - Electricity connection } \\
\text { - Modern sanitation facilities } \\
\text { (VIP Pit latrine/flush toilet) }\end{array}$ & $\begin{array}{l}\text { - Corrugated i } \\
\text { - Clean latrine }\end{array}$ & iron roof & $\begin{array}{l}\text { - Grass thatched roof } \\
\text { - No latrine }\end{array}$ \\
\hline Education Level & - Secondary & - Primary & & - No formal education \\
\hline Energy used & $\begin{array}{l}\text { - Charcoal, kerosene and/or } \\
\text { electricity }\end{array}$ & $\begin{array}{l}\text { - Charcoal } \\
\text { firewood }\end{array}$ & and/or & - Firewood \\
\hline
\end{tabular}

\subsection{Data Collection}

The researcher made two visits to selected study areas of Bagamoyo and Kigamboni and one visit to Tanga coastal areas. The first visit was specifically for pre-testing the questionnaire, as well as gathering baseline information, with respect to research objective one while collecting data for research question one. The researcher made one additional visit to carry out a full-scale repeat survey to capture seasonal changes.

Household survey was in the form of administration of questionnaire to women and men, and person-to-person interviews with at least one extra member of the household. The focus group discussions, pre-arranged by the village leaders, were conducted to community members composed of men and women, in each village.

\subsection{Data Analysis}

Analysis in this study was a continuous process which enabled to identify patterns emerging from the interviews. The findings of the analysis at every stage of the research process formed new objectives and research questions. The patterns were then used as new study guides during the data collection process. Explorative data analysis (EDA) was then employed to analyse quantitative data using descriptive, correlation and non-parametric analysis. Descriptive analysis focused mainly on frequency, descriptive statistics and cross-tabulation. The findings were then presented in the form of Tables, Plates and Charts.

\section{Results and Discussion}

\subsection{Respondents' Profile}

In the two areas Kigamboni and Bagamoyo an in-depth interviews were carried out with a sample of 100 respondents to get their views on the existing link between environment-poverty and gender. In Bagamoyo area whereas $24 \%$ of the interviewed respondents were female $76 \%$ were male. Similarly in Kigamboni area the 
majority of the interviewed respondents were male (76\%) compared to female (24\%). Compared to Tanga coastal area, the situation was almost the same with $60 \%(\mathrm{~N}=45)$ of the respondents being male.

\subsection{Resource Endowment}

Table 2 indicates the percentage of the interviewed respondents from different resource endowment groups in Bagamoyo, Kigamboni and Tanga sites. In Bagamoyo site, it was not easy to have interviewed any person regarded to be in the high resource endowed group as most of them were not at home; they work in Dar es Salaam and come very late to sleep in Bagamoyo where they have permanent residence. Nonetheless, male respondents were more resource endowed than female. For example $34 \%$ (or $\mathrm{N}=17$ ) of the respondents in Bagamoyo were in the medium endowed group. Out of these only 1 (or $2 \%$ ) was a female.

Table 2. Interviewed respondents based on the resource endowments in the area (\% responses)

\begin{tabular}{|c|c|c|c|c|c|c|c|c|c|}
\hline \multirow{2}{*}{$\begin{array}{l}\text { Resource } \\
\text { category }\end{array}$} & \multicolumn{3}{|c|}{ Bagamoyo $(\mathrm{N}=50)$} & \multicolumn{3}{|c|}{ Kigamboni $(\mathrm{N}=50)$} & \multicolumn{3}{|c|}{ Tanga $(N=45)$} \\
\hline & Male & Female & Total & Male & Female & Total & Male & Female & Total \\
\hline $\begin{array}{l}\text { High resource endowed } \\
\text { group }\end{array}$ & 0 & 0 & 0 & 6 & 2 & 8 & 0 & 0 & $\mathbf{0}$ \\
\hline $\begin{array}{l}\text { Medium resource } \\
\text { endowed group }\end{array}$ & 34 & 2 & 36 & 54 & 10 & 64 & 6.6 & 4.4 & 11 \\
\hline $\begin{array}{l}\text { Low resource endowed } \\
\text { group }\end{array}$ & 40 & 24 & 64 & 20 & 8 & 28 & 49 & 40 & 89 \\
\hline Total & & & 100 & & & 100 & & & 100 \\
\hline
\end{tabular}

\subsection{Livelihoods Activities}

In all sites majority of the respondents mentioned to depend on smallholding agriculture and fishing as the main economic activities. As summarised in Table 3, in Bagamoyo, majority of the people are engaged in crop production $(60 \%)$, although fishing has always been a dominant occupation of the coastal people. It would have been expected that the fishing activity would have been boosted by the increased number of tourist hotels.

The main livelihood activity of the respondents in Kigamboni and Tanga is fishing (43.8\%). This is due to the fact that Kigamboni being in proximity to Dar es Salaam city and very close to the ferry fish market, it is expected that the majority of the people in Kigamboni would engage themselves more in fishing than other activities. Other livelihood activities for Kigamboni, for example, include livestock keeping (4\%), petty business $(14 \%)$ and casual labour (2\%).

Table 3. Livelihood activities (\%responses)

\begin{tabular}{llllllllll}
\hline Livelihood activity & \multicolumn{3}{l}{ Bagamoyo $(\mathbf{N}=\mathbf{5 0})$} & \multicolumn{3}{c}{ Kigamboni $(\mathbf{N}=\mathbf{5 0})$} & \multicolumn{3}{c}{ Tanga $(\mathbf{N}=\mathbf{4 5})$} \\
& Male & Female & Total & Male & Female & Total & Male & Female & Total \\
\hline Crop production & 52 & 8 & 60 & 22 & 6 & 28 & 17.8 & 8.9 & $\mathbf{2 6 . 7}$ \\
Fishing & 14 & 6 & 20 & 42 & 2 & 44 & 24.4 & 17.8 & $\mathbf{4 2 . 2}$ \\
Livestock keeping & 4 & 0 & 4 & 2 & 0 & 2 & 2.2 & 2.2 & $\mathbf{4 . 4}$ \\
Casual labour & 0 & 2 & 2 & 2 & 2 & 4 & 2.2 & 2.2 & $\mathbf{4 . 4}$ \\
Petty business & 4 & 10 & 14 & 6 & 16 & 22 & 13.4 & 8.9 & $\mathbf{2 2 . 3}$ \\
\hline Total & & & $\mathbf{1 0 0}$ & & & $\mathbf{1 0 0}$ & & & $\mathbf{1 0 0}$ \\
\hline
\end{tabular}

Further analysis of the data in Table 3 show that female respondents (2\% and 10\%) in Kigamboni and Bagamoyo respectively, were found to be more engaged in casual labour and petty business than men $(0$ and $4 \%$ respectively). This is possibly attributed again by the proximity of Kigamboni to Dar es Salaam city. Being in proximity to Dar es Salaam city offers additional informal business opportunities to female. Few female respondents $(27.3 \%)$ or 12 out of 44 female respondents were engaged in fishing, which is only $8.3 \%$ of the total 
145 respondents. According to the rest of the female respondents fishing is considered hard work and a male domain because it requires a person to stay out of households for long durations and in most cases at night. Under these circumstances women would be forced to forsake their cultural and social household obligations. In view of the reported setback, female respondents said they would continue with their traditional income generating activities which include petty trading involving fish frying, food vending and items made from raffin palm.

\subsection{Status of Coastal Natural Resources}

A correlation was done between settlements location in relation to availability of natural resources before investigating the status of the resources. It was evident from observations, focus group discussions and key informants that formation of all the villages along the coastline of Bagamoyo, Kigamboni and Tanga was due to abundance of environmental resources such as coral reefs, mangrove forests, seagrass beds and fishing grounds were abundant and in proximity. The sustainability of the settlements was also reported, by respondents, to be much dependent on the ecological health of the coast, which threatens the ecology of the coast areas due to population growth and destructive human activities.

An ethno-botanical survey was carried out to identify different gender based natural resources used by people in Bagamoyo, Kigamboni and Tanga sites. Table 4 indicates different coastal natural resources mentioned to be utilized by people in the surveyed sites and the quantities harvested. The figures are by standards very low indicating that there has been overexploitation in the past and partly because of legal restrictions in access to the resources due to destructive harvest practices.

Table 4. Coastal natural resources

\begin{tabular}{lllll}
\hline Type of the resource & $\begin{array}{l}\text { Range of average } \\
\text { harvested/Month pange of average } \\
\text { household in Bagamoyo }\end{array}$ & $\begin{array}{l}\text { Range of average } \\
\text { harvested/Month per } \\
\text { household in Kigamboni }\end{array}$ & $\begin{array}{l}\text { ofarvested/Month } \\
\text { household in Tanga }\end{array}$ \\
\hline $\begin{array}{l}\text { Mangrove poles } \\
\text { (bundles) }\end{array}$ & $5-15$ & $1-13$ & $1-37$ \\
Fish (Kg) & $10-100$ & & $10-150$ \\
Typhae (bundles) & $8-32$ & $0.5-26$ & - \\
Sand (lorries) & $2-20$ & $0-1$ & - \\
Salt (Kg) & $1-50$ & $1-3$ & $1-3$ \\
Sea - weed (Kg) & $10-50$ & $1-3$ & $10-100$ \\
Charcoal (Bags) & $1-200$ & $1-4$ & - \\
Coral reefs & - & $5-20$ & $1-5$ \\
Sea-snails & - & - & $3-15$ \\
Fire wood (Bundles) & $3-15$ & - & $3-5$ \\
$\begin{array}{l}\text { Dried palm } \\
\text { (Bundles) }\end{array}$ & $3-5$ & $1-25$ & $1-20$ \\
$\begin{array}{l}\text { Others e.g. Ukindu, } \\
\text { Miaa (Bundles) }\end{array}$ & $1-20$ & & \\
\hline
\end{tabular}

The participatory socio-economic and resource assessment and focus group discussions identified key environmental issues and their perceived causes. Mangrove forests were said to be declining because of forest land conversion to agricultural land (rice farms), salt extraction, ponds for prawn and seaweed farming, pollution through using mangrove forests as rubbish sinks especially from the hotels built along sea fronts, clearing forests for fuel (charcoal-making), construction and boat building material (Plate 1), commercial projects such as construction of beach hotels. 

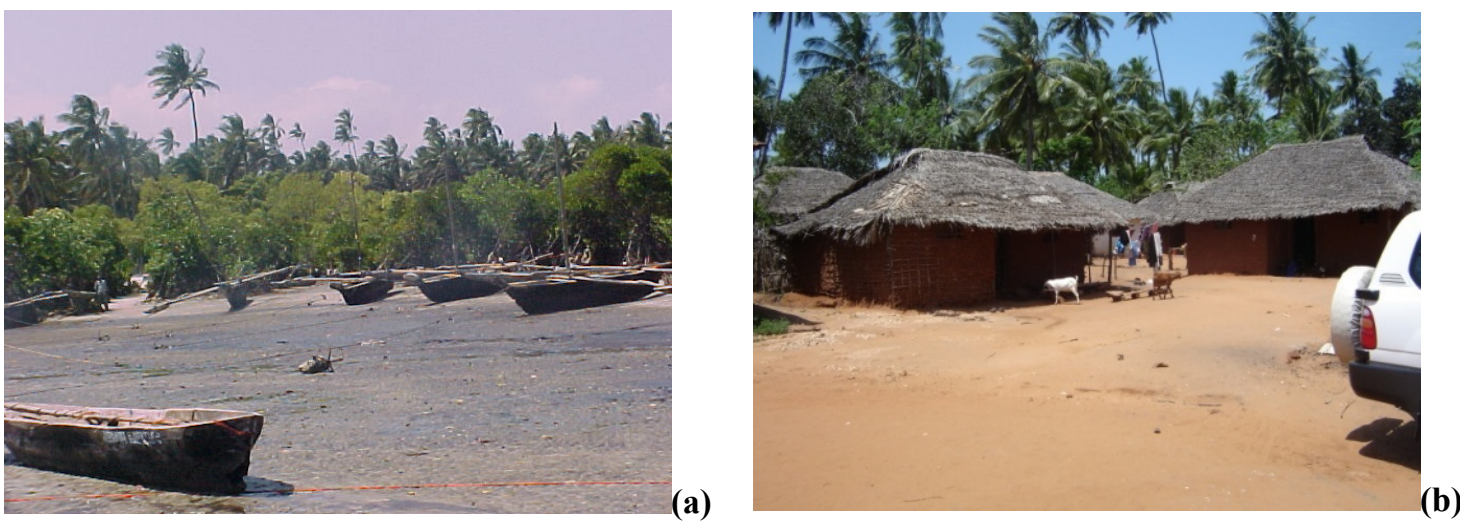

Plate 1. Mangrove forests and their products - boats (a) and houses (b)

The coral reefs have been destroyed by destructive fishing methods and practices like dynamite fishing, live coral mining, pollution from industrial waste (specifically Tanga coastline) and hotel rubbish, overexploitation of key species providing room for growth of undesirable organisms such as sea urchins and algae. The fish stock is also declining because of increasing demand for fishery resources due to population growth and tourism development especially in Bagamoyo and Kigamboni, this was said to have been caused by the use of destructive fishing methods and techniques including poison and small nets to increase harvest per fishing session, and indiscriminate cutting of mangrove tree specie that destroys the habitats.

\subsection{Gender-based Environmental Resources Entitlement}

\subsubsection{Gender Perception}

The respondents were also asked if they were aware of the gender concept. The question was set such that each respondent could accurately differentiate between gender and sex. It was learnt that the gender definition varied from the role of man and woman (30\%), relationship between man and woman (12\%), biological difference $(21 \%)$ to sexual harassment (5\%). The majority of the respondents in Bagamoyo (94.6\% and $53.8 \%)$ and Tanga $(77.8 \%$ and $66.7 \%)$ male and female respectively related gender with roles and responsibilities men and women have in a society (Table 5). This implies that the concept of gender is still referred to as biological differences.

Table 5. Respondents' awareness of gender concept (\% responses by sex)

\begin{tabular}{lllllll}
\hline Awareness & $\begin{array}{l}\text { Bagamoyo } \\
\text { Male }\end{array}$ & Female & $\begin{array}{l}\text { Kigamboni } \\
\text { Male }\end{array}$ & Female & $\begin{array}{l}\text { Tanga } \\
\text { Male }\end{array}$ & Female \\
\hline Aware & 94.6 & 53.8 & 45.9 & 23.1 & 77.8 & 66.7 \\
Not aware & 5.4 & 46.2 & 54.1 & 76.9 & 22.2 & 33.3 \\
\hline
\end{tabular}

\subsubsection{Access to Coastal Resources}

Analyses of the data from all study sites indicate that the main economic activity is fishing in the abundant and rich coral reefs. The majority of fishing vessels are dugout canoes and small wooden boats. However, Almost all the fishing (84\%), mainly offshore, is carried out by men (Figure 1), with the exception of shallow water shrimp farming which is accompanied with seaweed farming. The seaweed farm is shown in Plate 2 (a) and the harvest in Plate 2 (b). 


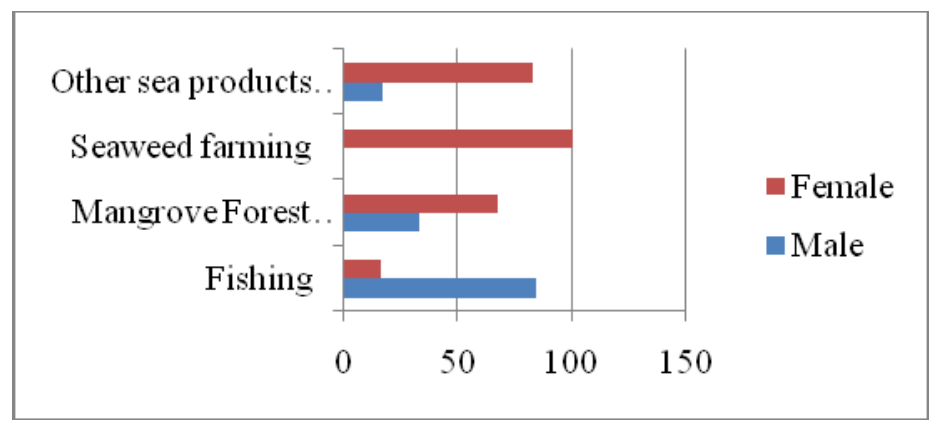

Figure 1. Primary resources used by sex (\% responses)

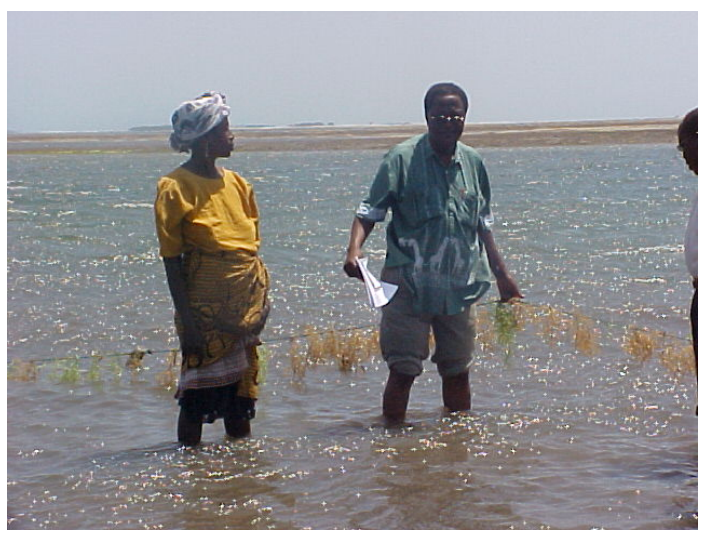

(a)

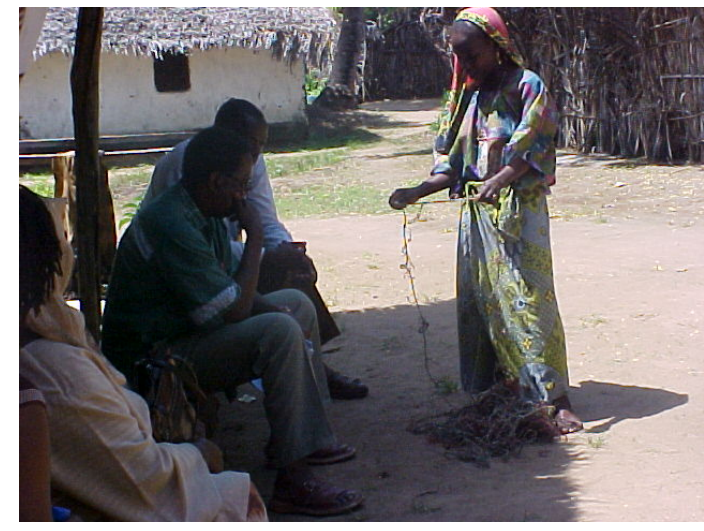

(b)

Plate 2. Seaweed farming in Tanga City Peri-urban

As reflected in Figure 1, besides seaweed farming female respondents said they were more engaged in mangrove forest harvest (67\%) specifically for firewood and building poles which they use as one of income generating source. The other activity related to coastal resources that preoccupy women is a collection of sea products for sale. This is wide spread in all study sites. Most of the farmers are women (55-80\%) said to be engaged in cultivation of rice (the main crop), maize, and cassava. They are also engaged in preparing and vending food, buying and selling processed (usually fried) fish, and trading household items bought from urban centres.

Further analysis was carried out to determine whether there was any relationship between physical endowments with access to coastal natural resources. The first correlation was between fishing gear and participation in fishing activities using Kendal's correlation. Kendal's correlation is a non-parametric measure of association for ranked values that ties into account. The sign of the resulting coefficient indicates the direction of the relation and its absolute value the strength, with the larger absolute values indicating stronger relationship. The coefficient of correlation between fishing gear and participation in fishing activities was 0.776 at .05 levels (1-tailed) of significance. This is a strong relationship implying that ownership of fishing gear increases access to fishing grounds.

The coefficient of correlation between agricultural land and participation in agricultural land was also determined using Pearson Correlation. The Pearson correlation was preferred here because the correlation coefficient, as a measure of linear association, would provide an indication to the significance ownership of land and access to land. The coefficient of correlation was .811 at .05 levels (2-tailed) of significance using a One Way ANOVA by Pearson correlation. This implied that land endowment increases participation in agricultural and seaweed farming activities.

\subsubsection{Ownership and Control over Coastal Natural Resources}

From focus group discussions and individual interviews it was evident that ownership and control over resources, which has a direct relationship with wealth or poverty, is achieved through several means. The mostly mentioned means were inheritance $(73 \%)$, purchase $(24 \%)$, gifts $(2 \%)$ and divorce $(1 \%)$. It was further revealed that different social interactions, networks and arrangements also determine and influence the patterns of ownership and control over resources between men and women. The Islamic culture, so dominantly practiced in the study 
areas, was cited as the major influence in the ownership and control pattern. Provisions for inheritance in the Islamic Religion, for example, give a woman a share that is only half of a male heir, it was revealed. The share given to a woman does not include tools and equipment necessary for income generating activities such as farming or fishing. This is attributed to the fact that physical endowment is defined in cultural norms by the activities performed by men. And when one wants to sell or give a gift to another, any of such physical endowment, the provisions for inheritance in the Islamic Religion are applied.

\subsection{Analysis of Trends and Factors Influencing Access to, Ownership and Control}

\subsubsection{Demographic Factors}

In focus group discussion it was unanimously agreed by both male and female discussants that women are still mainly involved in household activities that involve the collection of fuel wood, fetching water, cooking food and fishing for subsistence needs. On the other hand were said to be engaged in income generating activities such as food and cash crop cultivation, fishing and small scale business and trade. This has been the tradition and is still practiced. However, although widespread it was said that increasing poverty is putting new pressures on women to contribute to household income.

With only one or two exceptions, women's role relative to that of men, in the case study areas, is still perceived to be very low in areas of income generation, land ownership, contribution to household expenditure, community decision making and natural resource management. Women's role is deemed very high in time devoted to household activities. Nonetheless there is a recent trend of an increasing role shift for women especially to income generation, contribution to household expenditure and even in community decisions.

Major threats to gender equality as perceived by respondents were identified as to be inadequate production technologies, tools and equipment socially acceptable for women (46\%), inadequate education (37\%), low representation of women in decision-making bodies (11\%), and early marriage (6\%). As for education, only a small proportion of girls, complete primary school education. This observation is supported by the literacy of female respondents which was only $31 \%$. The difference in the educational levels between men and women was also said to account for important differences in outlook and priorities in gender issues and participation in income generating activities.

\subsubsection{Socio-economic/Cultural Factors}

In focus group discussions about existing practices in access to, ownership and control over resources it was general pointed out that women have different roles in the use of the coastal resource. It was further said that the relationship of women and with the environment is differentiated by their set of knowledge and skills they possessed. Female respondents mentioned to frequently and regularly exploit resources and ecological niches such as seaweed farming which has become predominantly women's economic activity now.

In the discussion it was also said that local beliefs and customs impose limits on fishing activities or on participation in fisheries with regard to women's biological differences with men such the women's menstrual blood would pollute the marine environment and/or chase away fish if they would go fishing during that time. Male local informants who do fishing said that during their fishing trips they avoid greeting women by hand. Some male respondents' fishermen even said it would be bad luck if they went out fishing after they had offered a handshake to their beloved wives.

\subsubsection{Policy and Legislation}

Interviews with enforcement bodies revealed that enforcement mechanisms of coastal and marine environments legislation, where appropriate, are weak and inefficient. The main problem is inadequate personnel at these levels who have limited facilities and finance necessary for law enforcement. The community members involved in fishing, especially women, practising seaweed farming and whole local communities regard the beach and the tidal-flat areas as common public spaces. With that respect they would like to have exclusive rights to these areas contrary and in conflict to the sustainable growth of the tourism industry.

Based on the findings above, an evaluation of some polices and legislation was carried out through focus group discussions. The review revealed that unilateral translations of the laws have in some cases developed into conflicts affecting access to, ownership and control over resource to both men and women. The conflicts, in which the government have inadequate enforcement resources, were categorised into three distinct areas in powers of the local authorities, fisheries, and government management systems and overlapping jurisdiction. A good example is the provisions of the Land Act 1999, Mining Act 2002 and the Local Government Authorities vide Local Government (District and Urban Authorities) Acts, 1982 on a piece of land. The following were observed as contradicting provisions: 
- The Mining Act 2002 allows for the granting of mining rights in protected areas, without consultation with the Minister responsible for land matters and/or protected areas;

- Existing legislation on land (Land Act, 1999) empowers the Commissioner of Lands to issue land titles where possibly salt could be produced. But the Mining Act 2002 empowers the Commission of Minerals to issue salt making licences. This is also contrary to the provisions of the National Land Policy (1995) for management of beaches;

- The government imposed a mangrove trees cutting ban in 1987 but the Local Government Authorities vide Local Government (District and Urban Authorities) Acts, 1982 and the Town and Country (Public Beaches Planning Area) Order, 1991 continue to issuing licences; and

- Although the Forestry Division has regulations that designate all mangrove forests as reserves, yet the ban on mangrove tree cutting was lifted in 1992. The Mangrove Project (using the National Forest Action Plan 1990/91-2007/08 and Management Plan for the Mangrove Ecosystem in Tanzania, 1991) now controls cutting. However, the Ministry of Industries and Trade has also power to issue permits for the extraction of salt in the same designated mangrove forest reserve areas in which the Fisheries Division issues permits for the development of prawn farms.

\subsection{Gender Based Responses to Access, Ownership and Control over Resources}

\subsubsection{Management of the Coastal Natural Resources in the Case Study Area}

Respondents in the area were interviewed on their perceptions regarding the management systems of the coastal natural resources. The responsible institutions and individuals that were mentioned to have a stake in managing and conserving the coastal natural resources, which have been useful resources for poverty alleviation in the area, were mention to be the central government through its natural resources management section and the community themselves.

Table 6 presents the percentage responses of the respondent in the case study areas on the awareness of the responsible institutions and individuals involved in managing the coastal natural resources in the area. In all cases the respondents consider that natural resources management is the responsibility of the government alienating themselves from the responsibility.

Table 6. Institutions and individuals involved in managing the coastal natural resources in the case study area (\% responses)

\begin{tabular}{llll}
\hline Responsible institution & Bagamoyo & Kigamboni & Tanga \\
\hline Government & 60 & 35 & 66 \\
Community & 7 & 23 & 23 \\
Both & 33 & 42 & 11 \\
& $\mathbf{1 0 0}$ & $\mathbf{1 0 0}$ & $\mathbf{1 0 0}$ \\
\hline
\end{tabular}

\section{Conclusion and Recommendations}

The study objective was to uncover gender relations in environmental entitlements and the ways they affect, constrain or diminish gender equity. Generally it has been observed that the majority of the community representatives are aware of the gender aspects and gender issues resulting into passive gender relations in the access to, control and use of natural resources in the areas surrounding seashores in Coastal regions in Tanzania.

It has also been established that women do not have an equal place with men through access to, control and ownership over coastal natural resources. While it was evident that coastal natural resources remain the main livelihood source of the community in the area, the big share of the income generated from utilisation of these resources is more under the control and custodian of males than female. This gender based utilisation of natural resources has inhibited economic growth of the communities and as a result there is low utilisation of the abundant coastal natural resources.

In all study areas, like any other coastal community, both men and women were found to play important but different productive, economic and social roles. Observed and documented was that effective access to, ownership and control over coastal natural resources is subject to gender relations. That each sex exerts differently over resources use based on religious and traditional beliefs, customs, social norms which govern 
interactions between people and between people and their environment in the study areas. These also frequently sanction the relationship of women with the environmental resources. Though the interactions are complex and dynamic, they were found to be of central importance in dictating how people use coastal natural resources, or at least in justifying and explaining how they are used. In some households in Tanga and part of Bagamoyo, for example, women are restricted to be in contact only within the family kinship and close family friends, particularly before marriage, during menstruation, before and after childbirth or following the death of the spouse. The taboos and restrictions are more often extended into women's contacts with natural resources such as fisheries, resulting into marginal fishing activities like seaweed farming to married or widowed women.

It was further noted that differences in household decision-making process apply not only to assets, household composition, natural resource endowment, and institutions, but are also driven by their preferences, and interests. The priorities of households to participate in activities that exploit natural resources and their management was found to differ because of men and women different capacities and powers to defend their interests. As observed by Sass (2002) there is a need to ensure opportunities for women to participate in decisions about environmental policies and programs at all levels, including roles as designers, planners, implementers, and evaluators. This would require open availability of information and equitable benefit sharing with communities involved that would greatly improve empowerment and improve gender relations in access to, ownership and control over natural coastal resources.

Furthermore, a better understanding of social networks is essential, especially by examining how these networks are established and their working mechanisms. This could offer more insight and lead to their improvement. Perhaps a better understanding of social networks is essential, especially by examining how these networks are established and their working mechanisms. This could offer more insight and lead to their improvement. Notably, a sociological research is needed into community social structures and culture in areas with extensive poverty and environmental degradation in order to better understand the relationships between those local structures, the broader political-economic structures, gender and the environment. We should not assume that all community structures are part of the solution; in many cases they are a key part of the problem, serving to maintain gender and class inequality, ethnic discrimination and political exclusion and inhibiting sustainable development.

Finally in terms of policy, again, there are several challenges. The study has pointed out that although to a great extent, religion, social and cultural contexts determine gender relations, laws prejudicial to women's rights and claims enshrine the relations. It is therefore necessary to include provisions, in Governing Constitutions, which emphasizes the need for women to access, own and control natural resources - land in particular - to bring about gender equity as a way of alleviating poverty among women and spearhead economic growth.

\section{Acknowledgement}

The author acknowledges Research on Poverty Alleviation (REPOA) for funding the research. The local government authorities and community members in the Districts of Bagamoyo (Pwani region), Kigamboni (Dar es Salaam region), and Tanga peri-urban are acknowledged for their assistance during data collection. Last but not least all persons that were involved in one way or another in the research process.

\section{References}

Agarwal, B. (2001). Gender and Land Rights Revisited: Exploring New Prospects via the State, Family and Market. Paper prepared for the UNRISD Project on Agrarian Change, Gender and Land Rights.

Andersson, J., \& Ngaz, Z. (1998). Coastal Communities' Production Choices, Risk Diversification, and Subsistence Behaviour: Responses in Periods of Transition, a Case Study from Tanzania. Ambio, 27(8), 686-693.

Francis, J., \& Bryceson, I. (2001). Tanzania Coastal and Marine Resources: Some Examples Illustrating Questions of Sustainable Use, in Lessons learned-case studies in Sustainable Use, pp. 76-102. Expert Africa, http://www.expertafrica.com/tanzania/zanzibar-island/reference-map

Jiddawi, N. S., \& Öhman, M. C. (2002), Marine Fisheries in Tanzania. Ambio, 31(7), 518-527. http://dx.doi.org/10.1579/0044-7447-31.7.518

Masalu, D. C. P. (2002). Coastal Erosion and Its Social and Environmental Aspects in Tanzania: A Case Study in Illegal Sand Mining. Coastal Management, 30(4), 347-359. http://dx.doi.org/10.1080/089207502900255

Semesi, A. K. (1998). Coastal Resources Utilization and Conservation Issues in Bagamoyo, Tanzania. Ambio, 27(8), 635-644.

Semesi, A. K., Mgaya, Y., Muruke, M., Francis, J., Julius, A., Lugomela, C., ... Kalangahe, B. (2001). Coastal 
resources of Bagamoyo District, $\quad$ Tanzania. $\quad$ Retrieved from http://gridnairobi.unep.org/chm/eafdocuments/Tanzania/semesi_p517-534.pdf

Sesabo, J. K., \& Tol, R. S. J. (2005). Factors affecting Income Strategies among households in Tanzanian Coastal Villages: Implications for Development-conservation initiatives. Working Paper FNU-70.

Sobo, F. (2003). Integrating Gender and Demography into Coastal Management Programs. Paper presented at the launching of the ICM programme in Tanzania.

Tanzania Coast Management Partnership (TCMP). (2000). Socio-economic Assessment of Tanzania's Coastal Resources. TCMP working document no. 5006.

Tanzania Coast Management Partnership (TCMP). (2003). The National ICM Strategy and Prospects for Poverty Reduction. State of the Coast Report, Tanzania Coastal Management Partnership.

Tietze, U., Groenewold, G., \& Marcoux, A., (2000). Demographic Chance in Coastal Fishing Communities and its Implication for the Coastal Environment. FAO Fisheries Technical Paper no. 403. Rome.

Torell, E., Mwanahija, S., Julius, F., Kalangahe, B., \& Munubi, R. (2007). Tanzania Biodiversity Threats Assessment: Biodiversity Threats and Management Opportunities for Fumba, Bagamoyo, and Mkuranga, Coastal Resources Center, University of Rhode Island, Narragansett, p. 47.

United Republic of Tanzania (URT). (2007), Coast Region Socio-economic Profile. National Bureau of Statistics and Coast Regional Commissioner's Office, Dar es Salaam, Tanzania.

van Ingen, T., Kawau, C., \& Wells, S. (2002). Gender Equity in Coastal Zone Management: Experiences from Tanga, Tanzania. IUCN Eastern Africa Regional Programme. 
Annex 1. Location of study sites in Tanzania

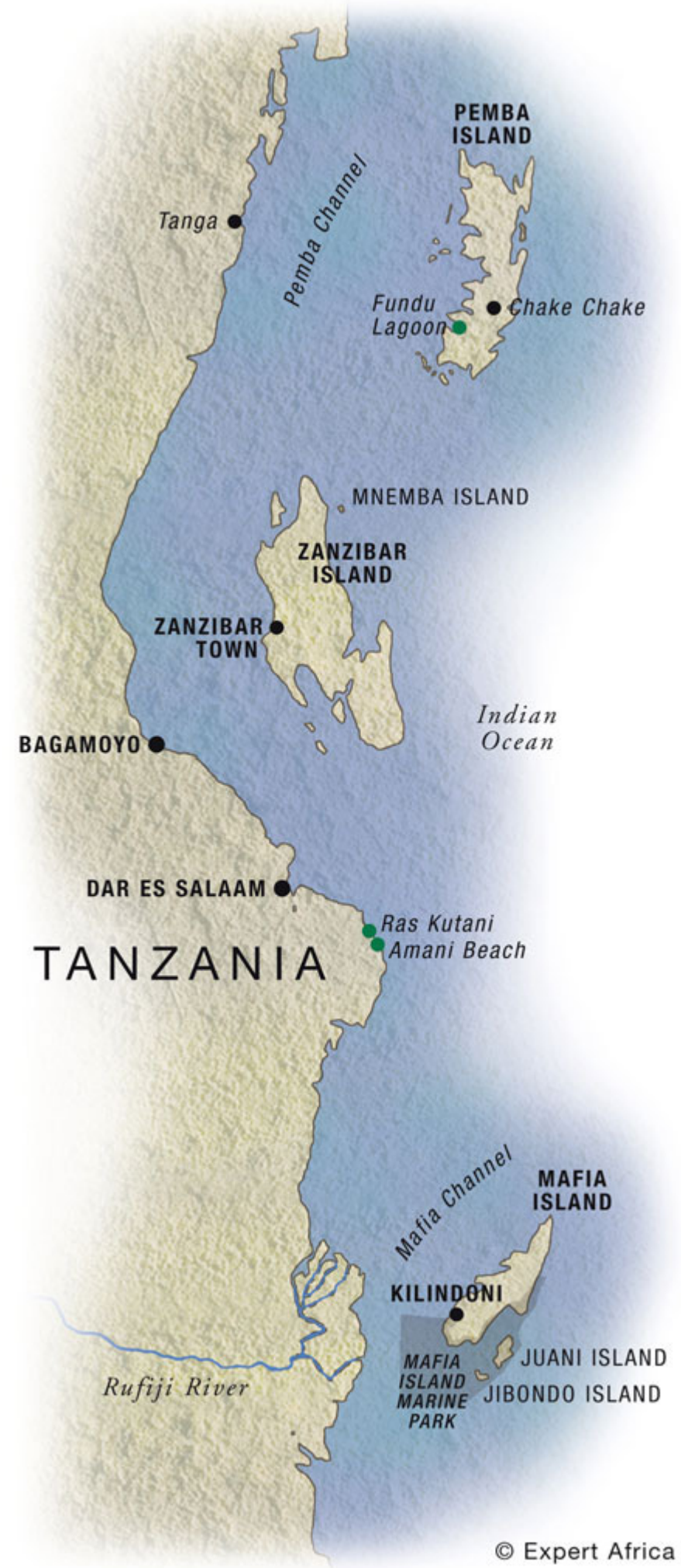


Annex 2. Map of Bagamoyo Coastal Area (Semesi, et al.)

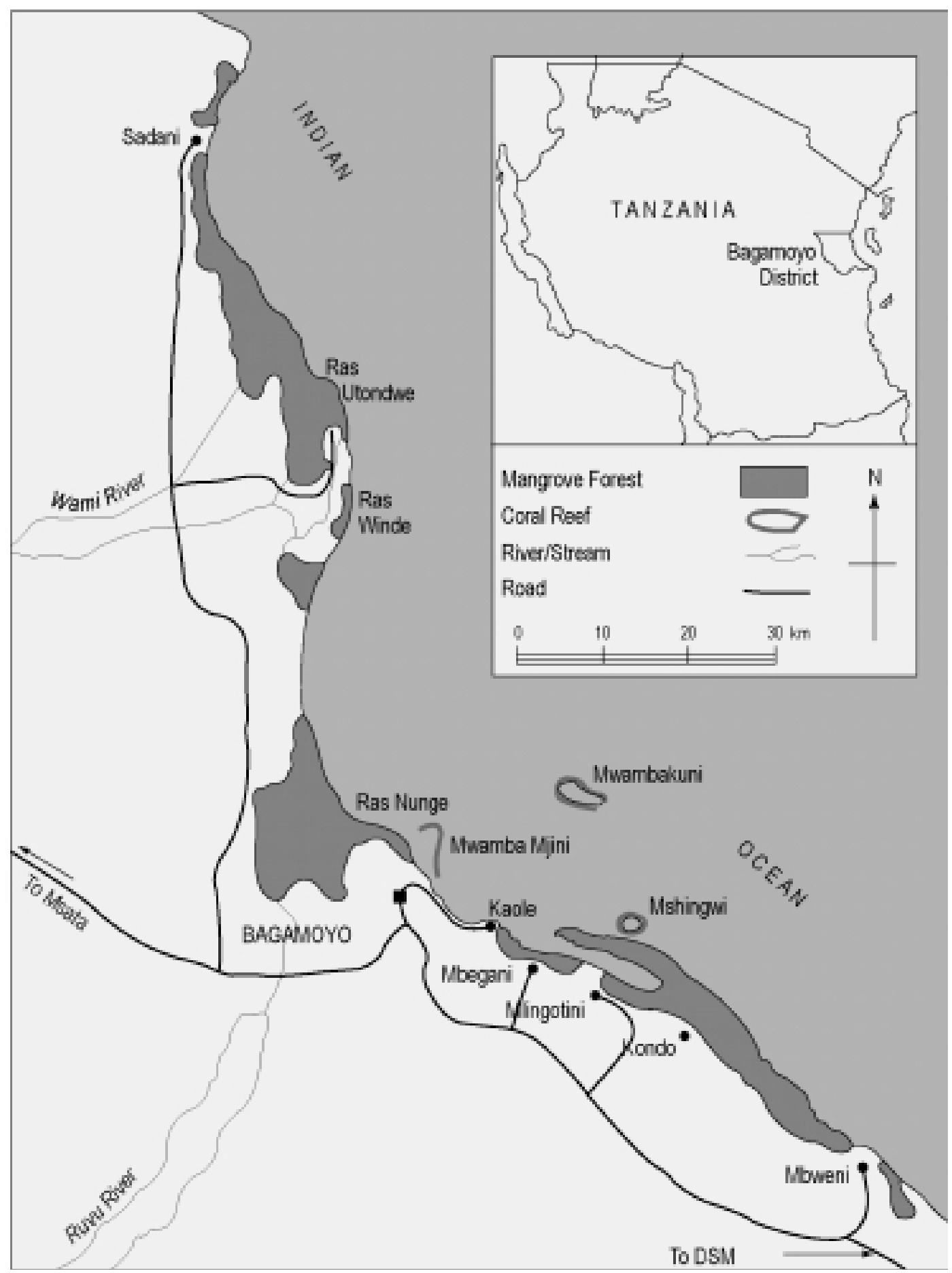




\section{Annex 3. Tanga Region (URT, 2008)}

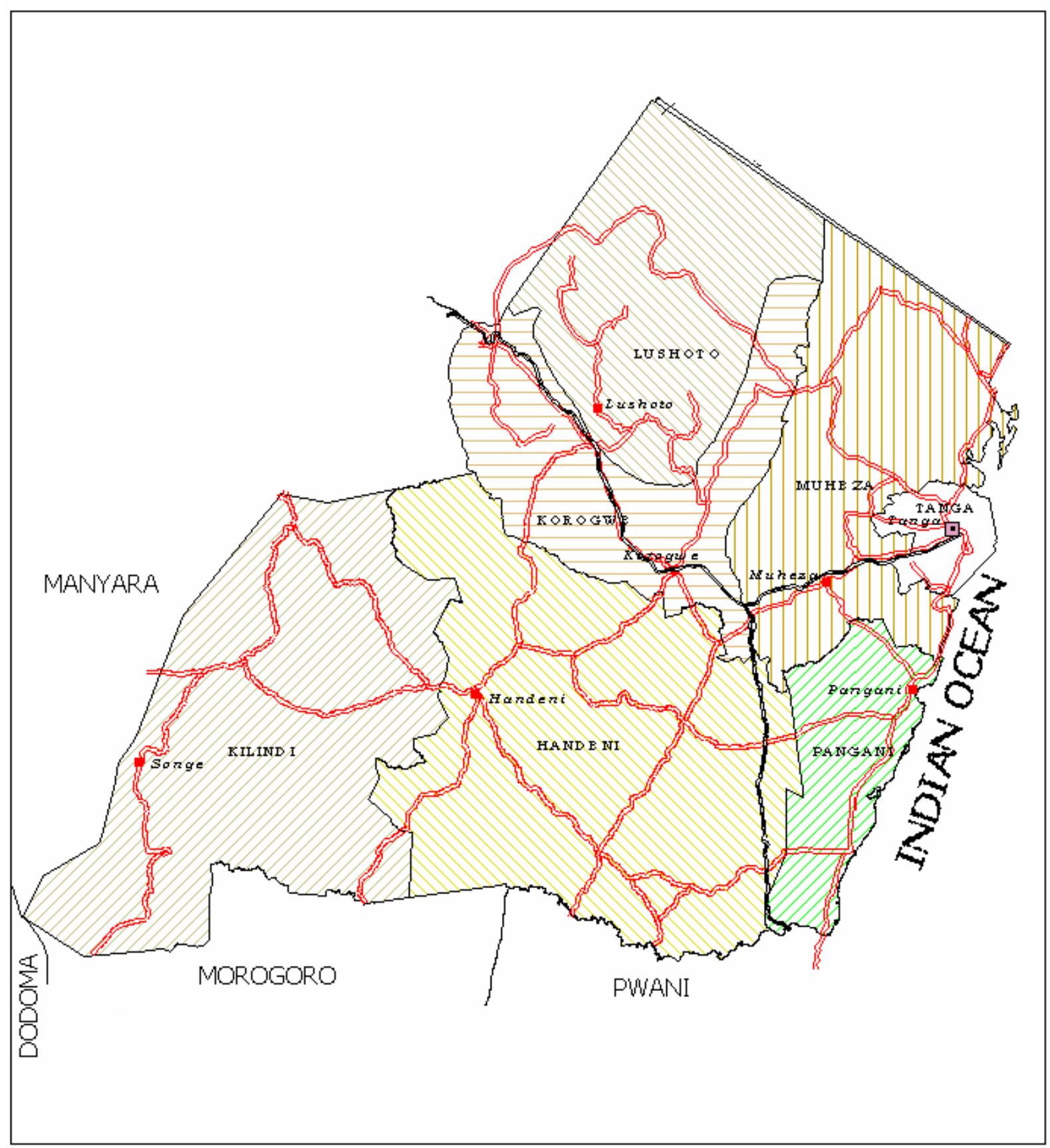




\section{Annex 4. Map of Dar es Salaam City Council showing Municipals (URT, 2004)}

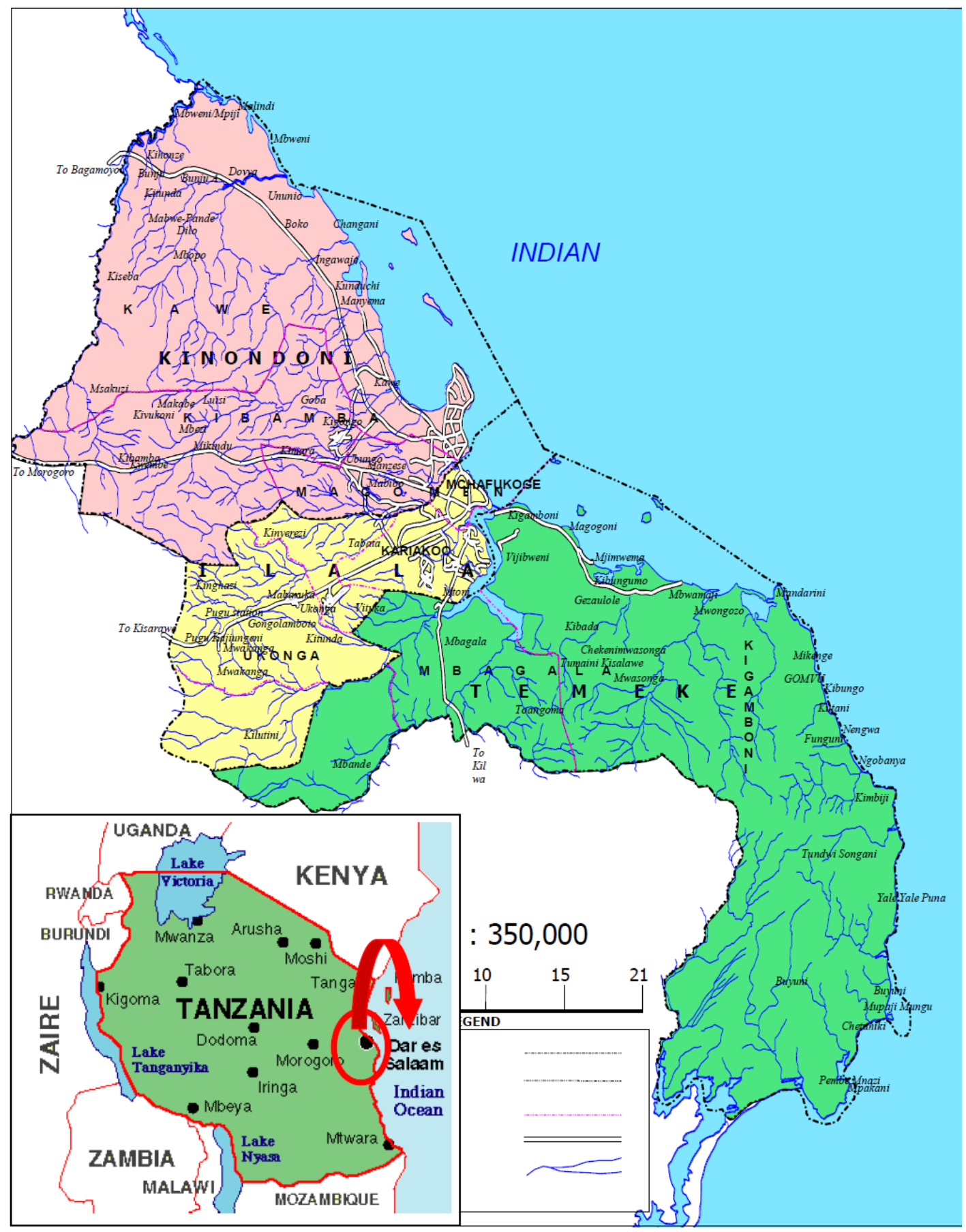

